\title{
Erratum to: Iatrogenic diplopia
}

\author{
Julio González-Martín-Moro • Julio José González-López • Marco Sales-Sanz • \\ Andrea Sales-Sanz • Javier González-Martín-Moro • Fernando Gómez-Sanz • \\ Mar González-Manrique • Belén Pilo-de-la-Fuente • Roberto García-Leal
}

Published online: 2 April 2014

(C) Springer Science+Business Media Dordrecht 2014

\section{Erratum to: Int Ophthalmol DOI 10.1007/s10792-014-9927-7}

In the title, the term Latrogenic is incorrectly used.

The correct title is Iatrogenic diplopia.

The authors apologize for this error.

The online version of the original article can be found under doi:10.1007/s10792-014-9927-7.

J. González-Martín-Moro ( $₫)$ · F. Gómez-Sanz Department of Ophthalmology, University Hospital of Henares, Av. Marie Curie sn, 28822 Coslada, Madrid, Spain

e-mail: juliogazpeitia@gmail.com; juliogmm@yahoo.es

J. González-Martín-Moro · M. González-Manrique

University Francisco de Vitoria, Madrid, Spain

J. J. González-López

Department of Ophthalmology, Moorfields Eye Hospital, London, UK

M. Sales-Sanz

Department of Ophthalmology, University Hospital

Ramón y Cajal, Madrid, Spain

A. Sales-Sanz

Rementería Eye Clinic, Madrid, Spain
J. González-Martín-Moro

Department of Oral and Maxillofacial surgery, La Paz

University Hospital, Madrid, Spain

F. Gómez-Sanz

School of Optometry, Complutense University, Madrid, Spain

M. González-Manrique

Department of Ophthalmology, University Hospital of

Móstoles, Madrid, Spain

B. Pilo-de-la-Fuente

Department of Neurology, University Hospital Infanta

Leonor, Leonor, Madrid, Spain

R. García-Leal

Department of Neurosurgery, General University Hospital Gregorio Marañón, Madrid, Spain 